In addition to its protective value this type of illumination, when the intensity is very low and the bulbs are suitably coloured, has; the advantage of giving a dim moonlight effect which is rathersoothing and somnolent to the patient and of differing little in. colour from the exterior illumination on a moonlight night. With this combination of night lamps and fixture when the light is made of the lowest possible intensity, little if any special curtaining is needed to give an effective blackout. The combination is more than adequate for what is called semi-blackout lighting. Ordinary blackout devices are difficult to provide and manage in a hospital for many reasons-convenience of operation, sanitation, continuity of operation, ventilation, etc. If in order to decrease both the amount and spread of the illumination it should be desired to shut off completely the upward component in the night light, this can be accomplished by blacking or otherwise light-proofing the upper half of the bulbs. Further, by extending the blacking, the downward component may be reduced to as near the threshold of vision as may be wanted. With this treatment of the night lamps in conjunction with the light-confining action of the fixture, every possible degree of blackout may be produced without resorting to special curtaining. The lamps that are used with this method of controlling the intensity and spread of the illumination may of course be colourless or of any colour that is preferred.

The need for protective lighting in hospitals is acute. Also a protective provision in the lighting itself is of great value in the night lighting of many places. As already indicated, there is, we believe, an important need for the special development of louvered, low-brightness lighting for protection in time of war.

\title{
A CASE OF MELANOTIC SARCOMA OF CONJUNCTIVA
}

BY

\section{HARRIS TOMKIN}

DUBLIN

A FEMALE patient aged 73 years presented herself for examination at the Eye Dispensary; County Hospital, Wexford, on February 10, 1942. She complained of a swelling on the left eye which she first noticed about 12 months ago as a small black spot. It gradually increased in size. On examination, a pear-shaped tumour was seen. projecting forward between the outer third of the left eyelids. Its base did not extend to the limbus but was abont 2 millimetres lateral to it. From base to apex it measured $8 \mathrm{~mm}$. and transversely. 
the tumour was $6 \mathrm{~mm}$. It was very deeply pigmented as regards the proximal $3 \mathrm{~mm}$. and likewise at the distal end for $2 \mathrm{~mm}$. but - the intermediate part was less pigmented. The conjunctival vessels were dilated and overran the surface of the tumour. Some pigmented spots were seen in the conjunctiva just outside the limbus

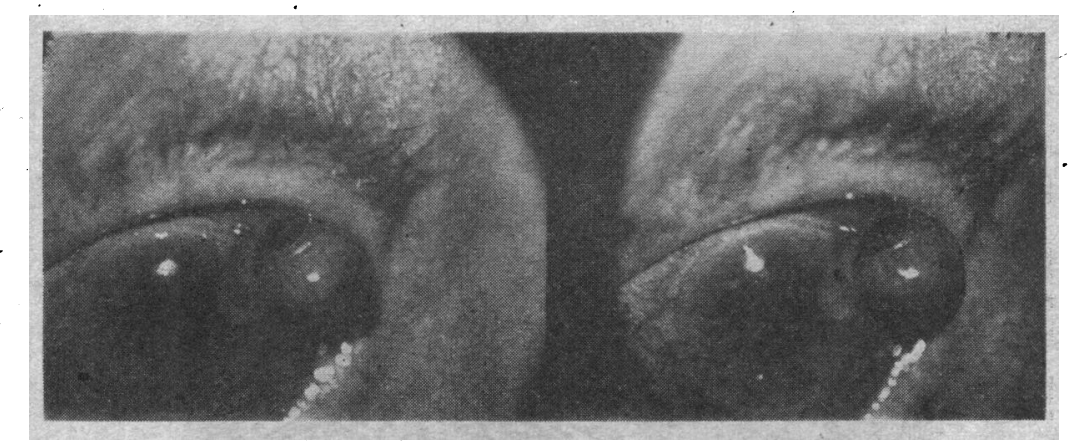

Stereoscopic photograph of case showing tumour projecting through lids and greyish area of cornea in its neighbourhood where abrasion had taken place.

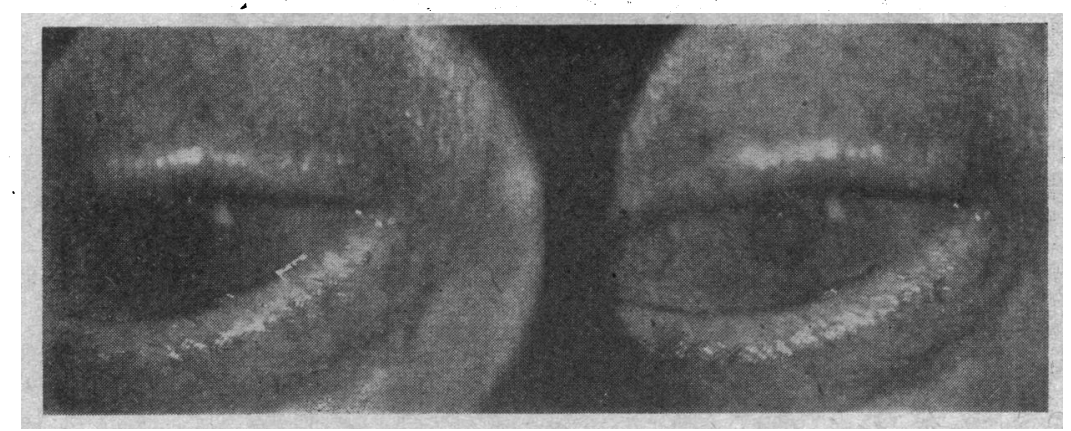

Photograph after removal of the growth.

at about " 5 o'clock." In this area the conjunctival vessels were again injected.

The cornea, in the neighbourhood of the tumour was abraded, probably by the tumour overhanging it.

The skin over the left zygoma showed a semilunar patch of, pigment about half the size of a florin. According to the patient this pigmented area had been present for the last ten years, and had not altered in size.

The patient was admitted to the Royal Victoria Eye and Ear Hospital, Dublin; and I incised the conjunctiva with curved scissors 
on the temporal. side of the tumourand undermined it to the limbus. Both the tumour and the pigmented area situated near the limbus at about " 5 o'clock" came away with the conjunctiva.

I saw the case again a month later. The eyeball was perfectly normal except for a small nebula of the cornea where it had been abraded by the tumour.

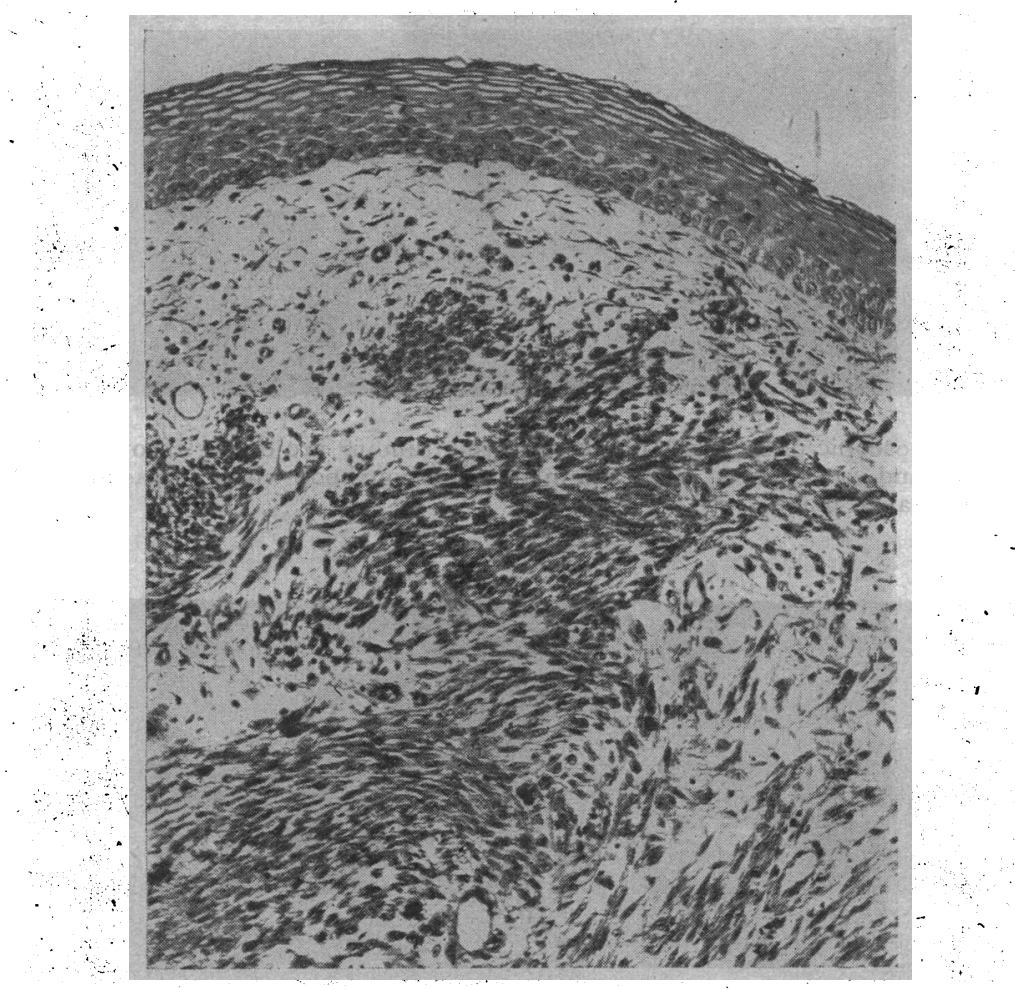

Microphotograph A $(\times 200)$ shows the epithelial and sub-epithelial portions and anterior part of the growth.

The tumour was examined by the pathologist to the Royal Victoria Eye and Ear Hospital, Dr. McCrea, who has kindly given me this report, together with the photographs of the sections.

The tissue was fixed in Zenker's solution and embedded in paraffin: Sections were stained with haematoxylin and eosin.

"The tissue sectioned is roughly circular in outline. The major portion is covered by stratified epithelium several layers thick and the remainder is enclosed in a delicate fibrous capsule. The superficial layers of the epithelium have degenerated.

The sub-epithelial layer, in extent from one-and-a-half to twice 
the thickness of the epithelium, comprises a fine reticular matrix, in which are scattered here and there, red blood cells, thin walled blood vessels, a-little scattered pigment both intra and extra cellular, and some tumour cells. Beneath this is the main mass of the neoplasm, consisting of spindle cells of varying sizes. These are

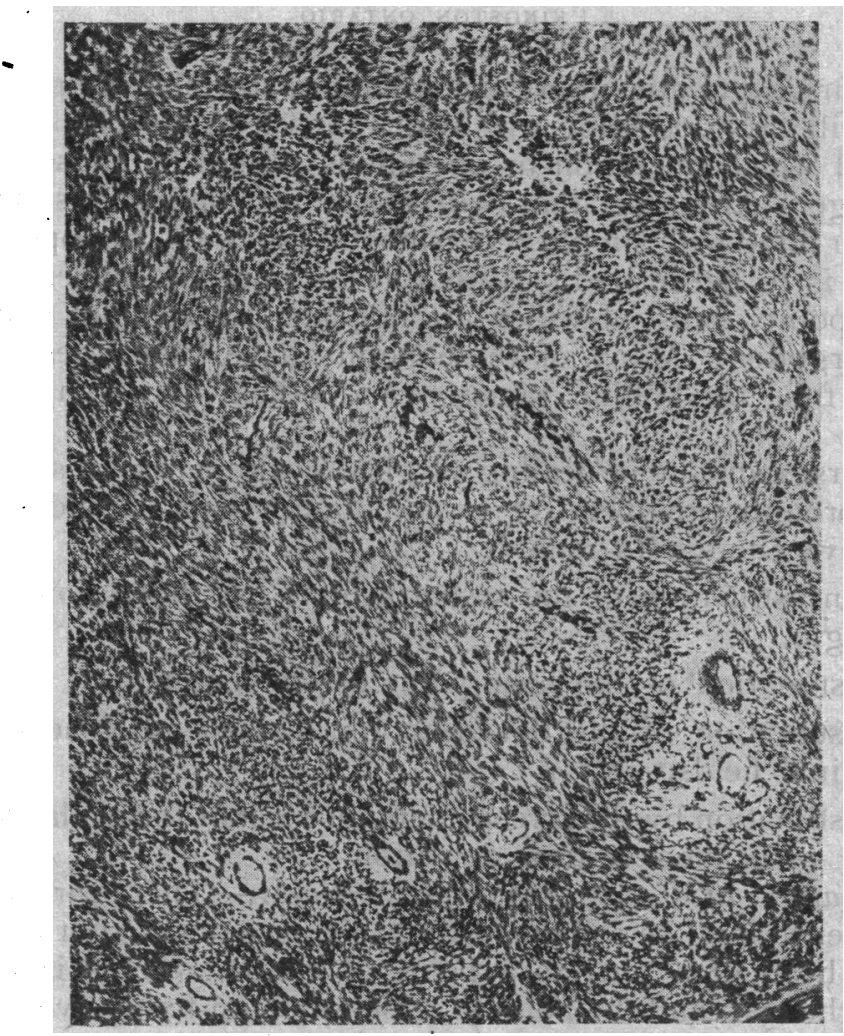

Microphotograph B $(\times 45)$ shows the main tumour mass. Pathological Diagnosis-Epibulbar Sarcoma.

mostly arranged in bundles in the long axis of the cell, whilst here and there they have been cut across at right angles to their long axis. There are occasional cells containing pigment, and some extra-cellular pigment is present also. On the whole, however, pigmentation is conspicuously absent.

The tumour matrix is a very delicate one. Primitive bloodvessels are numerous. 